\title{
Effects of acute exposure to low-dose radiation on the characteristics of human bone marrow mesenchymal stromal/stem cells
}

Aya Fujishiro ${ }^{1,2}$, Yasuo Miura ${ }^{1,4^{*}}$, Masaki Iwasa ${ }^{1,2}$, Sumie Fujii ${ }^{1,3}$, Noriko Sugino ${ }^{1,3}$, Akira Andoh ${ }^{2}$, Hideyo Hirai ${ }^{1}$, Taira Maekawa ${ }^{1}$ and Tatsuo Ichinohe ${ }^{4}$

\begin{abstract}
Background: In recent years, increasing attention has been paid to the effects of low-dose irradiation on human health. We examined whether low-dose irradiation affected the functions of mesenchymal stromal/stem cells (MSCs), which are tissue/organ-supportive stem cells, derived from bone marrow (BM).

Methods: Normal human BM-MSCs from five healthy individuals were used in this study. Culture-expanded BM-MSCs

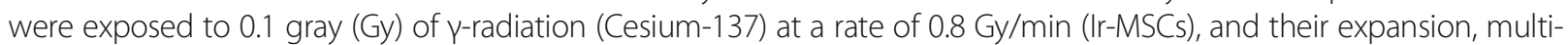
differentiation, and hematopoiesis-supportive capabilities were investigated.

Results: The expansion of BM-MSCs was transiently delayed after low-dose $\gamma$-irradiation compared with that of nonirradiated BM-MSCs (non-Ir-MSCs) in two out of five lots. Adipogenic and osteogenic differentiation capabilities were not significantly affected by low-dose irradiation, although one lot of BM-MSCs tended to have transiently reduced differentiation. When human BM hematopoietic stem/progenitor cells (HPCs) were co-cultured with Ir-MSCs, the generation of $\mathrm{CD}_{34}{ }^{+} \mathrm{CD} 38^{+}$cells from HPCs was enhanced compared with that in co-cultures with non-Ir-MSCs in two out of five lots. The mRNA expression level of interleukin (IL)- 6 was increased and those of stem cell factor (SCF) and fms-related tyrosine kinase 3 ligand (FIt $3 \mathrm{~L}$ ) were decreased in the affected lots of Ir-MSCs. In the other three lots of BM-MSCs, a cell growth delay, enhanced generation of $\mathrm{CD} 34^{+} \mathrm{CD} 38^{+}$cells from HPCs in co-culture, and a combination of increased expression of IL-6 and decreased expression of SCF and FIt3L were not observed. Of note, the characteristics of these affected Ir-MSCs recovered to a similar level as those of non-Ir-MSCs following culture for 3 weeks.
\end{abstract}

Conclusions: Our results suggest that acute exposure to low-dose (0.1 Gy) radiation can transiently affect the functional characteristics of human BM-MSCs.

Keywords: Bone marrow mesenchymal stromal/stem cells, Low-dose irradiation, Human

\section{Background}

Evaluation of the effects of low-dose irradiation is a medical and social issue for the health of patients who undergo computed tomography (CT) imaging for diagnosis, medical staff working in close proximity to

\footnotetext{
* Correspondence: ym58f5@kuhp.kyoto-u.ac.jp

'Department of Transfusion Medicine and Cell Therapy, Kyoto University Hospital, 54 Kawaharacho, Shogoin, Sakyo-ku, Kyoto 606-8507, Japan ${ }^{4}$ Department of Hematology and Oncology, Research Institute for Radiation Biology and Medicine, Hiroshima University, 1-2-3 Kasumi, Minamiku, Hiroshima 734-8553, Japan

Full list of author information is available at the end of the article
}

radioisotopes, engineers working in nuclear power plants, and survivors of nuclear accidents such as the Fukushima Daiichi Nuclear Power Plant accident in 2011. The deterministic effects of radiation influence the risk of diseases apart from cancers [1], i.e., there is no influence on the risk of these diseases by exposure to low-dose radiation of equal to or less than the threshold dose of 0.1 gray (Gy). However, recent epidemiological studies suggest that such low-dose irradiation increases the relative risk of ischemic or non-ischemic heart diseases, cerebrovascular disease, and cataracts $[2,3]$. 
Although not definitive, low-dose irradiation might affect the risk of a variety of non-malignant diseases as well as malignant diseases such as hematological malignancies [4].

In bone marrow (BM), there are two different types of stem/progenitor cells. With respect to hematopoiesis, hematopoietic stem/progenitor cells (HPCs) produce mature blood cells, and mesenchymal stromal/stem cells (MSCs) support this [5]. The influence of exposure to lowdose radiation on human HPCs has been investigated, and generation of both immature and mature hematopoietic cells from human HPCs is compromised $[6,7]$. On the other hand, the influence of exposure to low-dose radiation on MSCs is not known, although MSCs help to maintain the balance of bone/hematopoietic tissues as tissue-specific stem/progenitor cells in BM.

In this study, we examined whether low-dose irradiation affected the expansion, differentiation, and hematopoiesissupportive capability of human BM-MSCs.

\section{Methods}

\section{Reagents and antibodies}

Stem cell factor (SCF), interleukin (IL)-3, and fms-related tyrosine kinase 3 ligand (Flt3L) were purchased from Wako Pure Chemical Industries (Osaka, Japan). Thrombopoietin (TPO) was provided by Kyowa Hakko Kirin (Tokyo, Japan). A phycoerythrin (PE)-conjugated mouse anti-CD34 antibody (clone 563) and PE- or fluorescein isothiocyanate-conjugated mouse anti-CD45 antibodies (clone HI30) were purchased from BD Pharmingen (San Diego, CA). Allophycocyanin-conjugated mouse antiCD38 (clone HIT2) and anti-CD45 (clone 2D1) antibodies and PE-conjugated mouse anti-CD14 (clone 61D3), antiCD19 (clone SJ25C1), anti-CD73 (clone AD2), anti-CD90 (clone 5E10), and anti-CD105 (clone SN6) antibodies were from eBioscience (San Diego, CA).

\section{Isolation, expansion, and $\mathrm{\gamma}$-irradiation of BM-MSCs}

$\mathrm{BM}$ samples from healthy adult volunteers were purchased from AllCells (Emeryville, CA). BM-MSCs were isolated based on our previously published method $[8$, 9]. A single-cell suspension of $1 \times 10^{7} \mathrm{BM}$ mononuclear cells (MNCs) was seeded into T-75 culture flasks, and adherent cells were cultured in advanced-minimal essential medium (Invitrogen, Carlsbad, CA) supplemented with $5 \%$ fetal bovine serum (Invitrogen), $100 \mu \mathrm{M}$ ascorbic acid (Wako Pure Chemical Industries), $2 \mathrm{mM} \mathrm{L}$-glutamine, $100 \mathrm{U} / \mathrm{mL}$ penicillin, and $100 \mu \mathrm{g} / \mathrm{mL}$ streptomycin (all from Gibco, Carlsbad, CA). Primary cultures were passaged to disperse the colony-forming cells (passage 1). Cells at passage 3 were used as BM-MSCs in this study. Prior to experiments, the surface antigen profiles of CD14, CD19, CD34, CD45, CD73, CD90, and CD105 were examined by flow cytometric analysis to confirm that these cells expressed mesenchymal stem cell markers but did not express hematopoietic cell markers [10]. BM-MSCs were exposed to $0.1 \mathrm{~Gy} \gamma$-radiation (Cesium-137) at a rate of $0.8 \mathrm{~Gy} / \mathrm{min}$ using a Gammacell Irradiator (Best Theratronics, Ontario, Canada). Unless specified, $\gamma$ irradiated BM-MSCs (Ir-MSCs) were applied to the subsequent experiments at $24 \mathrm{~h}$ after irradiation (early phase). In some experiments, Ir-MSCs were cultured for a further 2-3 weeks after $\gamma$-irradiation and then applied to the subsequent experiments (late phase). To examine the effect of high-dose $\gamma$-radiation as a positive control, BM-MSCs were exposed to 4 Gy $\gamma$-radiation (H-MSCs) and were applied to the subsequent experiments. The study protocol was approved by the ethics committee of Kyoto University. For the cell expansion assay, BM-MSCs were seeded at a density of $5 \times 10^{4}$ cells $/ 10 \mathrm{~cm}$ dish and $\gamma$-irradiated, and then the number of cells was counted by $0.5 \%$ trypan blue staining weekly until they became confluent.

\section{Microarray analysis}

Total RNA was isolated from Ir-MSCs and BMMSCs that had not been exposed to 0.1 Gy $\gamma$ radiation (non-Ir-MSCs) using an RNeasy Mini Kit (Qiagen, Hilden, Germany). The RNA integrity of all samples was evaluated using an Agilent 2100 Bioanalyzer (Agilent Technologies, Santa Clara, CA) and an Agilent RNA 6000 Nano Kit (Agilent Technologies). A total of 150 ng RNA extracted from each sample was used to synthesize complementary DNA (cDNA) and complementary RNA (cRNA), and cRNA was labeled with Cyanine3. This was performed using a Low Input Quick Amp Labeling Kit, One-Color (Agilent Technologies). Hybridization was performed using a SurePrint G3 Human GE Microarray Kit (Agilent Technologies). Scanning and digitization of the microarray were performed using an Agilent Microarray Scanner G2565CA (Agilent Technologies) and Agilent Feature Extraction 11.0.1.1 (Agilent Technologies), respectively. Data normalization and expression analysis were performed using GeneSpring software version 13.1 (Agilent Technologies). Genes that were significantly up or downregulated in Ir-MSCs compared with non-Ir-MSCs were further analyzed by Gene Ontology (GO) classification, pathway analysis (Single Experiment Analysis [SEA] using Wikipathways; http://www.wikipathways.org), and Gene Set Enrichment Analysis ([GSEA]; GSEA v2.0.14 software, http://www.broadinstitute.org/gsea/index.jsp) [11-18]. Microarray data were submitted to the Gene Expression Omnibus of NCBI under the accession number GSE97368. 
Table 1 List of primer sets and universal probes for quantitative real-time PCR.

\begin{tabular}{llll}
\hline Gene & Forward primer ( $\left(^{\prime}-3^{\prime}\right)$ & Reverse primer (5'-3') & Universal probe (\#) \\
\hline Ang-1 & gacagatgttgagacccaggta & tgcttctctagcttgtaggtgga & 67 \\
Flt3L & ggccgaaatgacagtgct & agcagcaggaggagataggtt & 1 \\
GAPDH & agccacatcgctcagacac & gcccaatacgaccaaatcc & 60 \\
IL-6 & gatgagtacaaaagtcctgatcca & ctgcagccactggttctgt & 40 \\
Jag-1 & ggcaacaccttcaacctca & gcctccacaagcaacgtatag & 28 \\
LIF & tgccaatgccctctttattc & gtccaggttgttggggaac & 26 \\
SCF & gcgctgcctttccttatg & ccttcagtttgacgagagga & 68 \\
FABP4 & ccaccataaagagaaaacgagag & gtggaagtgacgcctttcat & 77 \\
Runx2 & ctaccaccccgctgtcttc & aaaaagggcccagttctga & 4
\end{tabular}

Ang-1 angiopoietin-1, Flt3L fms-related tyrosine kinase 3 ligand, GAPDH glyceraldehyde-3-phosphate dehydrogenase, IL-6 interleukin-6, Jag-1 jagged-1, LIF leukemia inhibitory factor, SCF stem cell factor, FABP4 fatty acid-binding protein 4, Runx2 runt-related transcription factor 2

\section{In vitro differentiation assays of BM-MSCs}

To induce osteogenic differentiation of BM-MSCs, osteogenesis-inducing cocktails of $100 \mu \mathrm{M}$ ascorbic acid, $1.8 \mathrm{mM}$ potassium dihydrogen phosphate (Sigma-Aldrich, St. Louis, MO), and 100 nM dexamethasone (Sigma-Aldrich) were added to the culture media. Mineralization was evaluated by $1 \%$ Alizarin Red S staining after 6 weeks of osteogenesis-inducing culture. To induce adipogenic differentiation of BMMSCs, $0.5 \mathrm{mM}$ isobutyl-methylxanthine, $60 \mu \mathrm{M}$ indomethacin, $0.5 \mu \mathrm{M}$ hydrocortisone, and $10 \mu \mathrm{g} / \mathrm{mL}$ insulin (all from Sigma-Aldrich) were added to the culture media. Oil Red $\mathrm{O}$ staining was used to assess lipid-laden fat cells after 3 weeks of adipogenesisinducing culture. The Alizarin Red S-stained area and the number of Oil Red $\mathrm{O}^{+}$cells were quantitated as previously described [9, 19]. Images were acquired using an Axiovert 40C microscope (Carl Zeiss, Oberkochen, Germany). In some experiments, expression of the adipogenic gene fatty acid-binding protein 4 (FABP4) and the osteogenic gene runt-related transcription factor 2 (Runx2) in H-MSCs was assessed by quantitative real-time PCR.

\section{Co-culture assays of CD34 ${ }^{+}$HPCs and BM-MSCs}

Human CD34 ${ }^{+}$HPCs were isolated from BM-MNCs using anti-CD34 immunomagnetic microbeads (Miltenyi Biotec, Bergisch Gladbach, Germany). BM-MSCs $(5 \times$ $10^{4}$ ) were seeded into a 24-well culture plate and exposed to 0.1 Gy $\gamma$-radiation. Then, $0.6 \times 10^{3} \mathrm{HPCs}$ were applied to the BM-MSCs and co-cultured in StemSpan
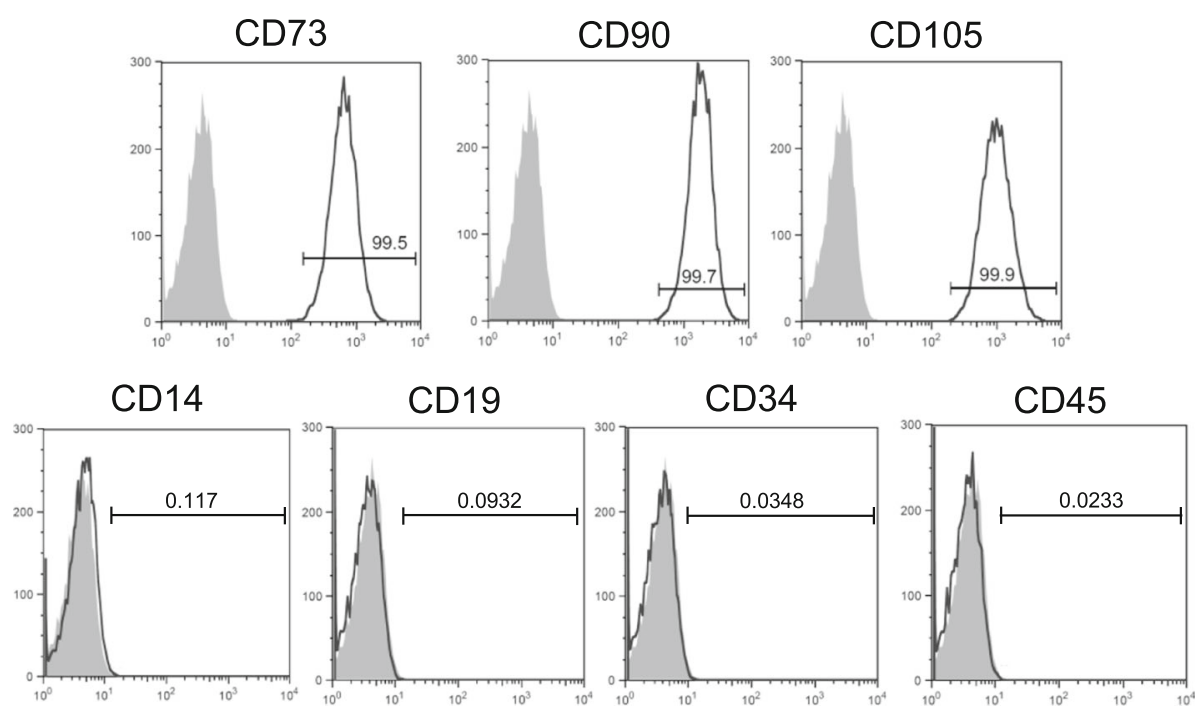

Fig. 1 Surface marker expression of human BM-MSCs. Flow cytometric analysis shows that lot A of BM-MSCs is positive for mesenchymal stem cell-associated surface markers (CD73, CD90, and CD105) and is negative for hematopoietic cell-associated surface markers (CD14, CD19, CD34, and CD45). Filled histograms indicate control staining. Numbers in each histogram indicate the percentage of cells. The same surface marker expression profiles were confirmed in lots B-E of BM-MSCs 
a

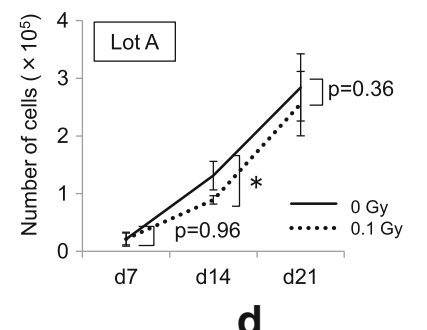

C

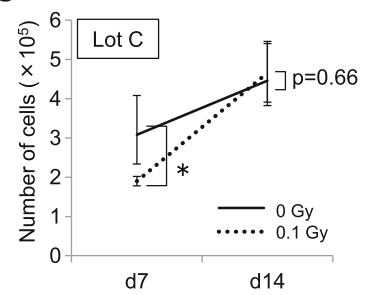

b
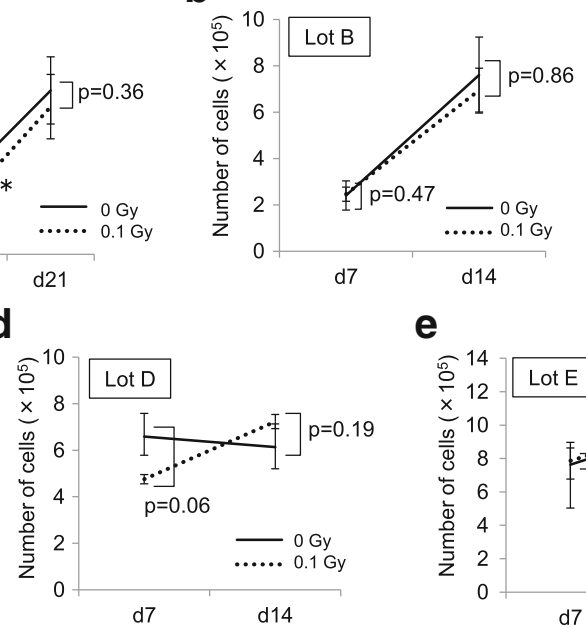

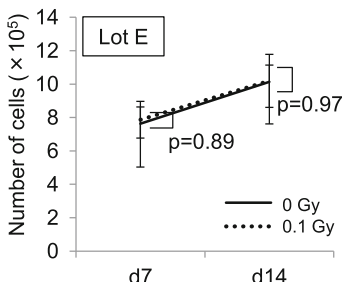

Fig. 2 Expansion of Ir-MSCs. (a-e) BM-MSCs (lots A-E) were exposed to (Ir-MSCs, dotted lines) or not exposed to (non-Ir-MSCs, solid lines) 0.1 Gy $\gamma$-radiation on day 0 . They were then cultured until confluent. The number of viable cells was counted weekly after $\gamma$-irradiation using $0.5 \%$ trypan blue. Data are mean values \pm SD. $n=5$ per group $(\mathbf{a}-\mathbf{c})$ or $n=3$ per group $(\mathbf{d}, \mathbf{e}) .{ }^{*}, p<0.05$

Serum-Free Expansion Medium (STEMCELL Technologies, Vancouver, Canada) supplemented with $100 \mathrm{ng} / \mathrm{mL}$ SCF, $100 \mathrm{ng} / \mathrm{mL}$ Flt3L, $50 \mathrm{ng} / \mathrm{mL}$ TPO, and $20 \mathrm{ng} / \mathrm{mL}$ IL-3. After 10 days of co-culture, the number and surface marker expression of hematopoietic cells were examined by flow cytometric analysis.

\section{Quantitative real-time PCR}

Total RNA was extracted using the QIAamp RNA Blood Mini Kit (Qiagen) and subjected to reverse transcription. The $10 \mu \mathrm{L}$ PCR mixture contained Taqman Fast Universal PCR master mix (Applied Biosystems, Carlsbad, CA), cDNA, primer pairs, and the Taqman probe (Universal

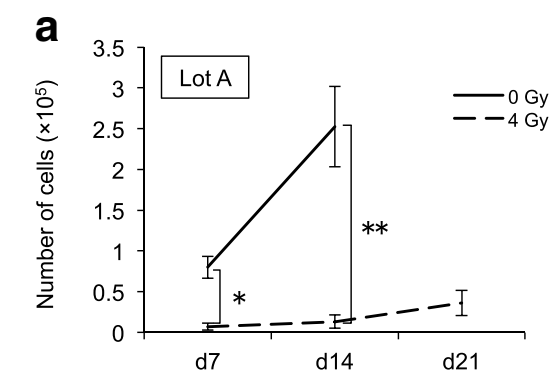

C
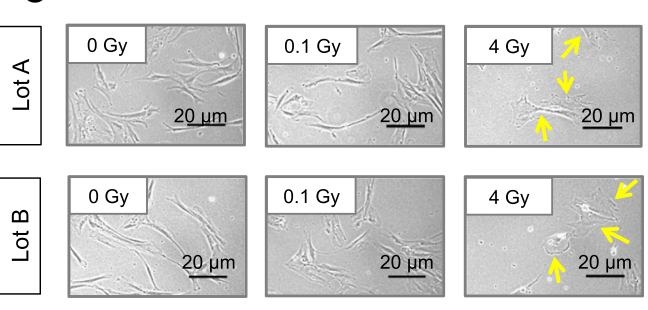

b

d

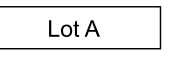

e
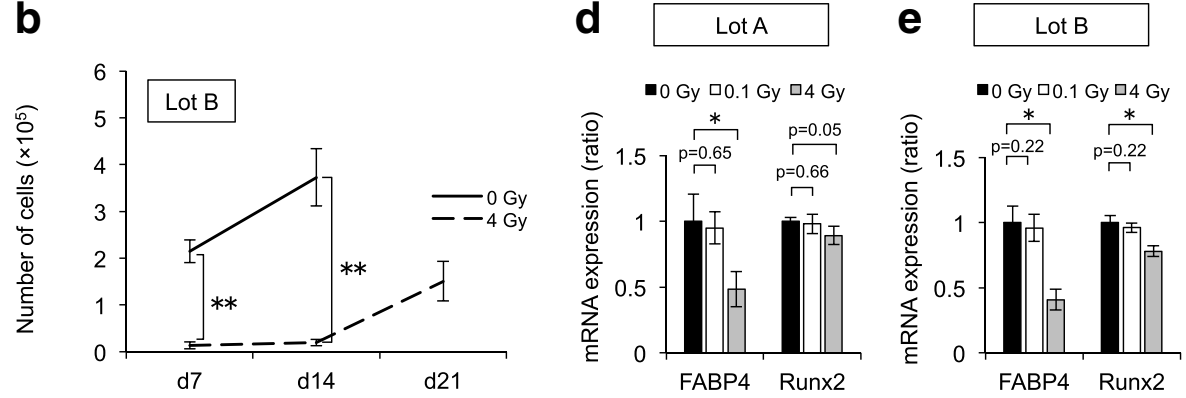

Fig. 3 Characteristics of H-MSCs. BM-MSCs (lots A and B) were exposed to 4 Gy (H-MSCs) or 0.1 Gy (Ir-MSCs) Y-radiation, or were not exposed to Y-radiation (non-Ir-MSCs). (a, b) Expansion of lots A and B of H-MSCs (dashed lines) and non-Ir-MSCs (solid lines). The number of viable cells was counted weekly after $\gamma$-irradiation using $0.5 \%$ trypan blue. (c) Morphology of lots A and B of H-MSCs, Ir-MSCs, and non-Ir-MSCs. Representative phase contrast images are shown. Yellow arrows indicate H-MSCs. Bars, $20 \mu \mathrm{m}$. (d, e) Expression of adipogenic and osteogenic markers in lots A and B of H-MSCs (gray bars), Ir-MSCs (open bars), and non-Ir-MSCs (solid bars), as assessed by quantitative real-time PCR. Expression in H-MSCs and Ir-MSCS is shown relative to that in non-Ir-MSCs. Data are mean values \pm SD $(\mathbf{a}, \mathbf{b}, \mathbf{d}, \mathbf{e}) . n=4$ per group $(\mathbf{a}, \mathbf{d})$ or $n=5$ per group $(\mathbf{b}, \mathbf{e}) .{ }^{*}, p<0.05 ;{ }^{* *}, p<0.01$ 
Probe Library). cDNA was amplified with the Step One Plus Real-Time PCR System (Applied Biosystems) using the following parameters: $95{ }^{\circ} \mathrm{C}$ for $20 \mathrm{~s}$, followed by 40 cycles of $95{ }^{\circ} \mathrm{C}$ for $1 \mathrm{~s}$ and $60{ }^{\circ} \mathrm{C}$ for $20 \mathrm{~s}$. Glyceraldehyde-3-phosphate dehydrogenase was used as an internal control to normalize any loading differences. The primer sets and universal probes used are listed in Table 1.

\section{Statistical analysis}

The unpaired Student's $t$ test was used for analysis, unless otherwise indicated. Data in bar graphs indicate the mean \pm standard deviation (SD). Statistical significance is expressed as follows: ${ }^{*}, p<0.05 ;{ }^{* *}, p<0.01$; n.s., not significant.

\section{Results}

\section{Expansion of Ir-MSCs}

Five lots of human BM-MSCs (lots A-E) were tested in this study. These cells were positive for mesenchymal stem cell-associated markers including CD73, CD90, and CD105 and were negative for hematopoietic cellassociated markers including CD14, CD19, CD34, and CD45 (Fig. 1). Each lot of BM-MSCs was exposed to 0.1 Gy $\gamma$-radiation, and then their expansion was evaluated. In lot A, the number of Ir-MSCs on day 14 after $\gamma$-irradiation was lower than the number of non-IrMSCs (Fig. 2a). On the other hand, the numbers of IrMSCs and non-Ir-MSCs did not differ in lot B (Fig. 2b). With regard to the other three lots of BM-MSCs, the number of Ir-MSCs on day 7 after $\gamma$-irradiation was lower than the number of non-Ir-MSCs in one lot (lot C, Fig. 2c), and there was no difference between the numbers of Ir-MSCs and non-Ir-MSCs in the other two lots (lots D and E, Fig. 2d, e). Of note, in lots A and C, the number of Ir-MSCs recovered to a level similar to the number of non-Ir-MSCs by culture for 3 weeks after $\gamma$-irradiation (Fig. 2a, c). Therefore, BM-MSCs were divided into two groups based on their expansion response to acute exposure to low-dose $\gamma$-radiation. One group included BM-MSCs whose expansion was not affected by exposure to low-dose $\gamma$-radiation. The other group included BM-MSCs that showed a transient expansion delay upon exposure to low-dose $\gamma$-radiation. In lots $\mathrm{A}$ and $\mathrm{B}$, the number of $\mathrm{H}-\mathrm{MSCs}$ was consistently lower than the number of non-Ir-MSCs (Fig. 3a, b). HMSCs changed their morphology from a spindle shape to an enlarged and irregular shape, whereas the morphology of Ir-MSCs was comparable to that of non-Ir-MSCs (Fig. 3c).

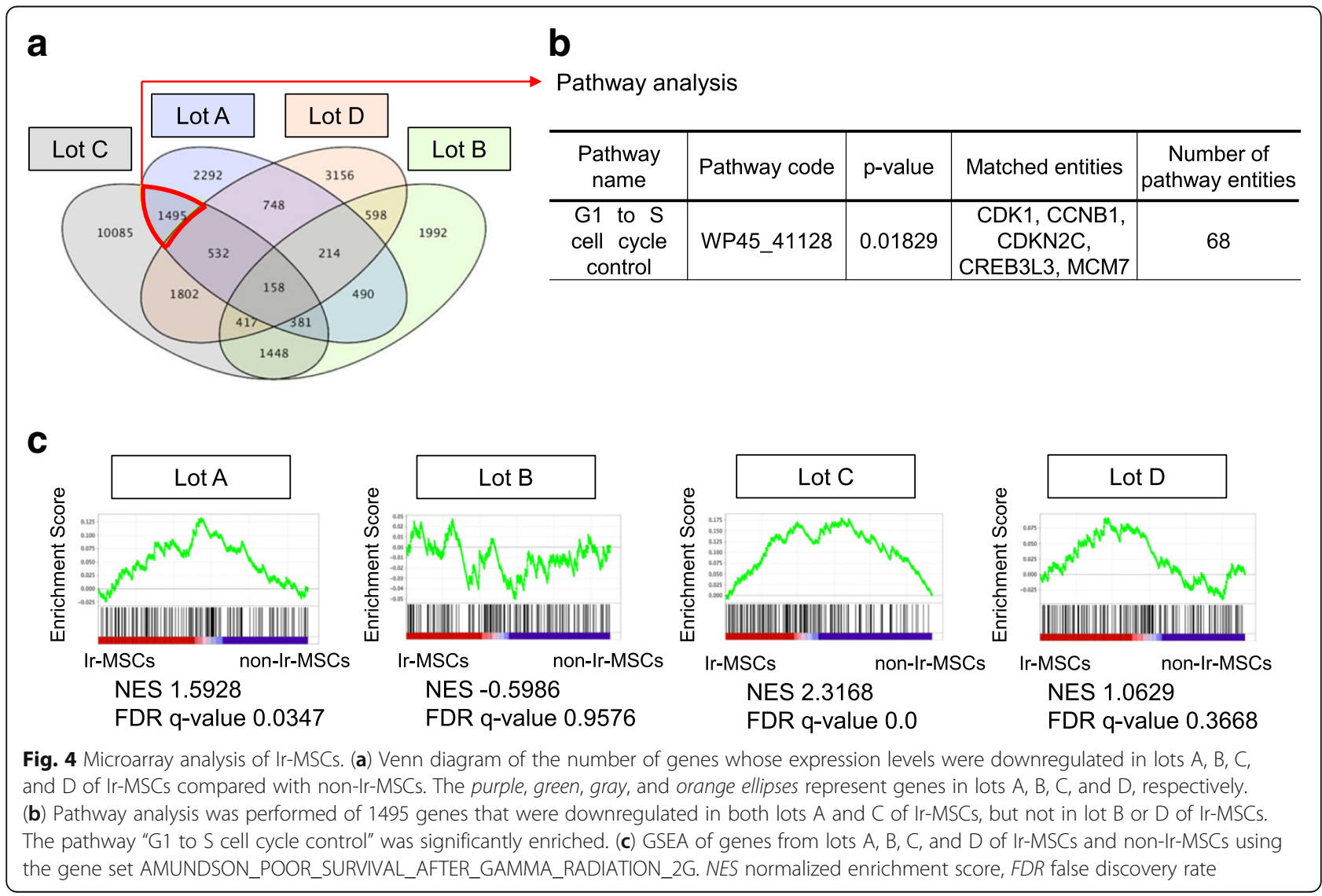


We performed microarray analysis using RNA extracted from Ir-MSCs and non-Ir-MSCs. The number of genes that were upregulated in Ir-MSCs relative to non-Ir-MSCs (fold change >1.2) was 8290, 5510, 6252, and 8383 in lots A, B, C, and D, respectively. Among them, 783 genes were commonly upregulated only in lots A and C of Ir-MSCs, which showed an expansion delay after $\gamma$-irradiation. SEA of these 783 genes identified three pathways with significant changes; however, they were not associated with well-known functions of MSCs. The number of genes that were downregulated in Ir-MSCs relative to non-Ir-MSCs (fold change $>1.2$ ) was $6310,5698,16,318$, and 7625 in lots $A, B, C$, and D, respectively (Fig. 4a). Among them, 1495 genes were commonly downregulated only in lots A and C. SEA of these 1495 genes identified seven pathways with significant changes, including a cell cycle-associated pathway (Fig. 4b). We also performed GSEA of genes from both Ir-MSCs and non-Ir-MSCs, and found that the gene set "AMUNDSON_POOR_SURVIVAL_AFTER_ GAMMA_RADIATION_2G" was highly enriched in lots A and C of Ir-MSCs, but not in lot B or D of IrMSCs (Fig. 4c). This gene set consists of genes that are upregulated in the 60 damaged cell lines of the National Cancer Institute Anticancer Drug Screen (NCI-60) after genotoxic stress induced by 2 Gy $\gamma$ irradiation [20]. This result suggests that stress in IrMSCs was comparable to that induced by 2 Gy $\gamma$ irradiation.

\section{Adipogenic and osteogenic differentiation capabilities of Ir-MSCs}

A multi-differentiation capability is one of the fundamental characteristics of human BM-MSCs. We examined the influence of acute exposure to 0.1 Gy $\gamma$-radiation on the adipogenic and osteogenic differentiation of BM-MSCs. Although not statistically significant, Ir-MSCs tended to show reduced adipogenic and osteogenic differentiation capabilities in lot $\mathrm{A}$, as assessed by Oil Red $\mathrm{O}$ staining (Fig. 5a, b) and Alizarin Red $\mathrm{S}$ staining (Fig. 5c, d), respectively. In the other lots of BMMSCs, there was no difference in the level of fat deposition between adipogenically differentiated Ir-MSCs and non-Ir-MSCs (Fig. 6a-c). With regard to the level of mineralization, there was no difference between a

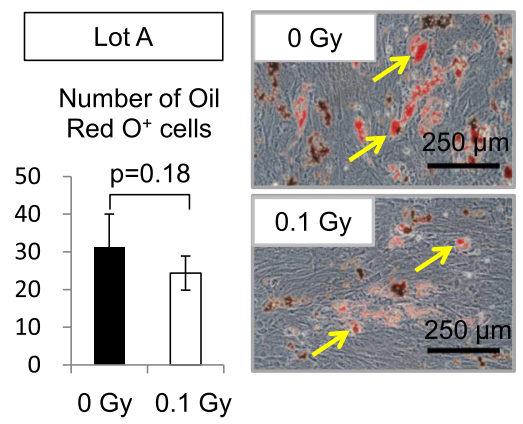

e

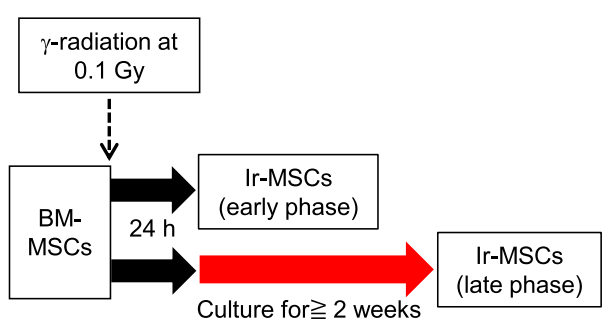

C

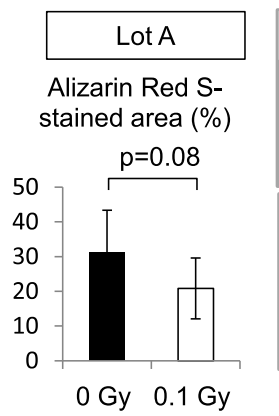

f

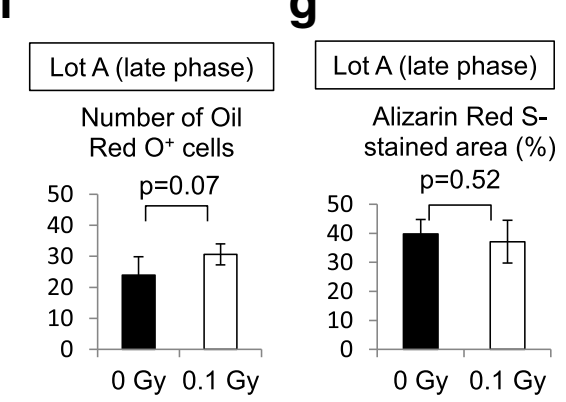

Fig. 5 Adipogenic and osteogenic differentiation of Ir-MSCs. (a) Quantitative measurement of the adipogenic differentiation of lot A of BM-MSCS

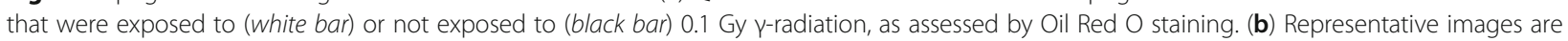
shown. Yellow arrows indicate lipid-laden fat cells. Bars 250 um. (c) Quantitative measurement of the osteogenic differentiation of lot A of BMMSCs that were exposed to (white bar) or not exposed to (black bar) 0.1 Gy $\gamma$-radiation, as assessed by Alizarin Red S staining. (d) Representative images are shown. Bars $250 \mu \mathrm{m}$. (e- $\mathbf{g})$ Adipogenic and osteogenic differentiation of Ir-MSCs at the late phase. (e) Schema of culture of BM-MSCS after -irradiation. $(\mathbf{f}, \mathbf{g})$ Quantitative measurement of the adipogenic $(\mathbf{f})$ and osteogenic $(\mathbf{g})$ differentiation of lot A of BM-MSCs that were exposed to (white bars) or not exposed to (black bars) 0.1 Gy -radiation and then cultured for a further 3 weeks (Ir-MSCs at late phase), as assessed by Oil Red $O$ staining and Alizarin Red S staining, respectively. $(\mathbf{a}, \mathbf{c}, \mathbf{f}, \mathbf{g})$ Data are mean values $\pm S D . n=5$ per group 
osteogenically differentiated Ir-MSCs and non-IrMSCs in all lots except for lot D (Fig. 6d-f). We performed the same experiments using lot A of BMMSCs that had been cultured for a further 2 weeks after $\gamma$-irradiation (Fig. 5e, late phase). Their differentiation capabilities were similar to those of non-IrMSCs (Fig. 5f, g). We examined expression of the adipogenic gene FABP4 and the osteogenic master gene Runx2 in lots A and B of H-MSCs. Their expression was low in both lots of H-MSCs compared with that in non-Ir-MSCs, whereas it was comparable in Ir-MSCs and non-Ir-MSCs (Fig. 3d, e).

\section{Hematopoiesis-supportive capability of Ir-MSCs}

We examined whether the capability of BM-MSCs to support hematopoiesis was affected by low-dose $\gamma$ irradiation. Twenty-four hours after $\gamma$-irradiation, IrMSCs were co-cultured with CD $34^{+}$HPCs in vitro. In lot $\mathrm{A}$, the generation of $\mathrm{CD} 45^{+}$cells, total $\mathrm{CD} 34^{+}$cells, and $\mathrm{CD} 34^{+} \mathrm{CD} 38^{-}$cells from HPCs did not significantly differ between co-cultures with Ir-MSCs and co-cultures with non-Ir-MSCs. However, the generation of $\mathrm{CD}_{3} 4^{+} \mathrm{CD} 38^{+}$ cells was enhanced in co-cultures with Ir-MSCs compared with that in co-cultures with non-Ir-MSCs (Fig. 7a, b). In lot $\mathrm{B}$, the generation of $\mathrm{CD} 34^{+} \mathrm{CD} 38^{+}$cells as well as that of $\mathrm{CD} 45^{+}$cells, total $\mathrm{CD} 34^{+}$cells, and CD34 ${ }^{+} \mathrm{CD} 38^{-}$cells in co-cultures with Ir-MSCs was similar to that in co-cultures with non-Ir-MSCs (Fig. 7c, d). When the same experiments were performed using the other three lots of BM-MSCs (lots C, D, and E), the enhanced generation of $\mathrm{CD}_{34}{ }^{+} \mathrm{CD} 38^{+}$cells was observed in lot $\mathrm{C}$, but not in lots D and E (Fig. 8a-C). Thus, BM-MSCs were divided into two groups based on their response to acute exposure to low-dose $\gamma$-radiation. One group included BM-MSCs whose capability to support hematopoietic cell generation from HPCs in co-cultures was not affected by exposure to $0.1 \mathrm{~Gy} \gamma$-radiation. The other group included BM-MSCs whose hematopoiesis-supportive capability was affected by such $\gamma$-irradiation.

\section{Increased IL-6 expression and decreased SCF and Flt3L expression in Ir-MSCs that show an altered hematopoiesis- supportive capability}

We next explored the expression levels of hematopoiesisassociated molecules in Ir-MSCs. In lot A, the mRNA expression level of IL-6 was higher and those of SCF and Flt3L were lower in Ir-MSCs than in non-IrMSCs (Fig. 9a). With regard to other hematopoiesis- a
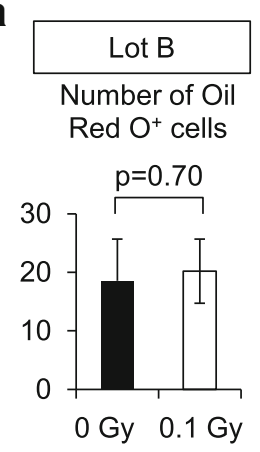

d
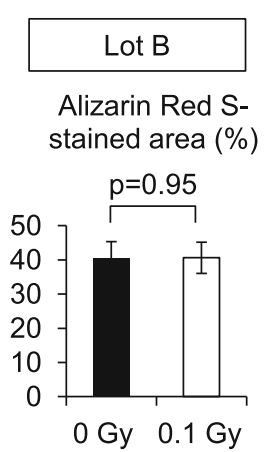

b
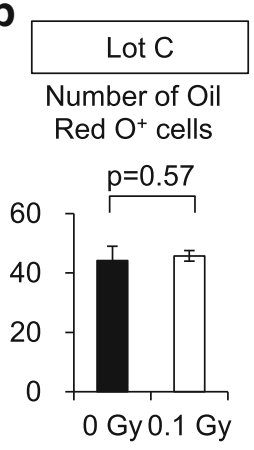

e

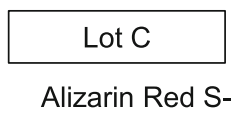

stained area $(\%)$

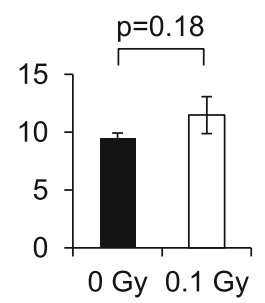

C
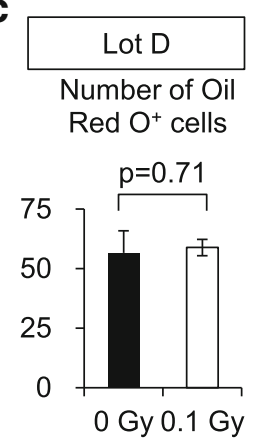

f
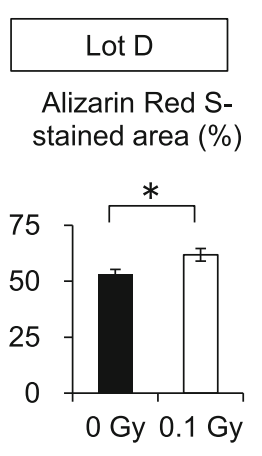

Fig. 6 Adipogenic and osteogenic differentiation of three different lots of Ir-MSCs. (a-c) Quantitative measurement of the adipogenic differentiation of three different lots of BM-MSCs (lots B, C, and D) that were exposed to (white bars) or not exposed to (black bars) 0.1 Gy Y-radiation, as assessed by Oil Red $O$ staining. (d-f) Quantitative measurement of the osteogenic differentiation of three different lots of BM-MSCs (lots B, C, and D) that were exposed to (white bars) or not exposed to (black bars) 0.1 Gy -radiation, as assessed by Alizarin Red S staining. Lot E of BM-MSCs was unavailable for this analysis due to an inadequate number of cells. Data are mean values \pm SD. $n=4$ per group $(\mathbf{a}, \mathbf{d})$ or $n=3$ per group $(\mathbf{b}, \mathbf{c}, \mathbf{e}, \mathbf{f}){ }^{*}, p<0.05$ 

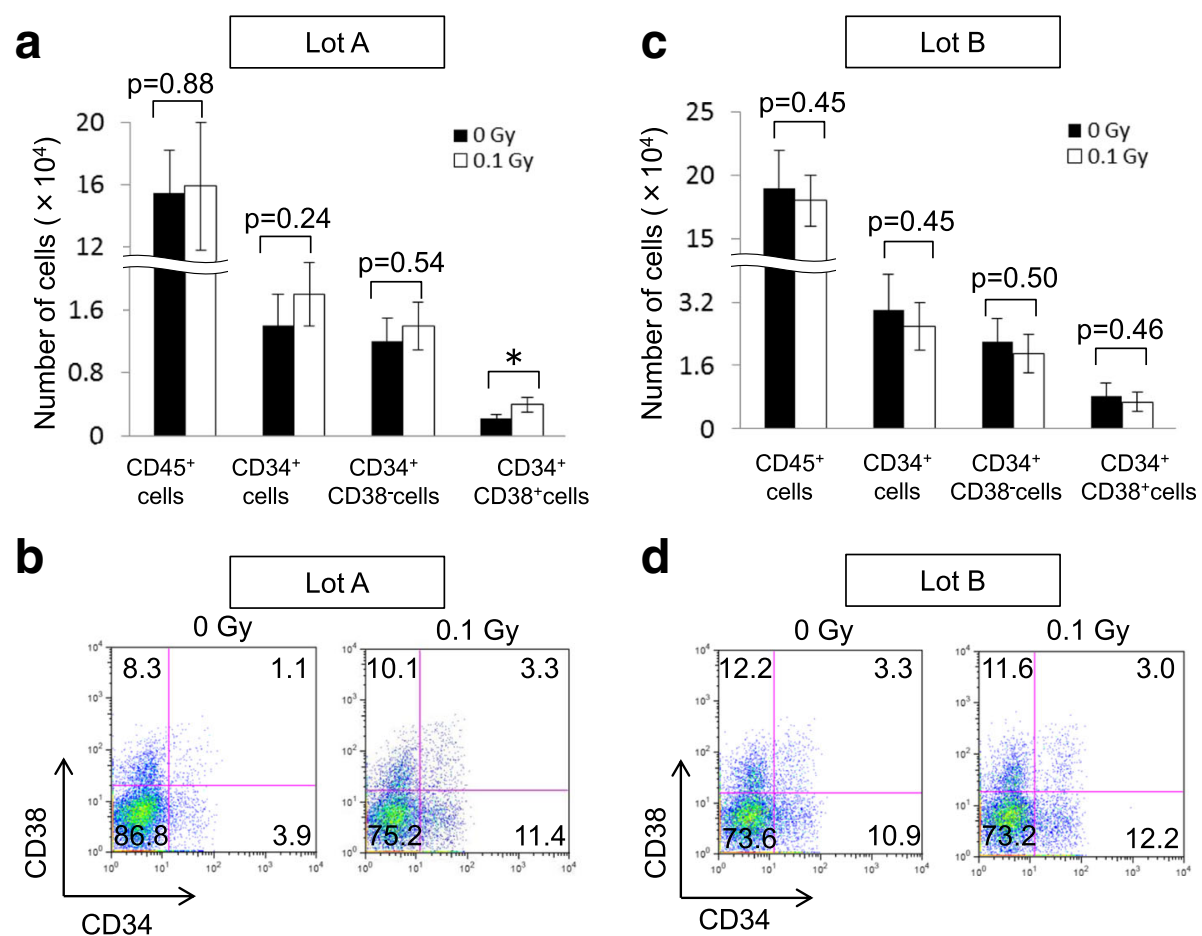

Fig. 7 Co-culture of HPCs with Ir-MSCs. Flow cytometric analysis showing the generation of hematopoietic cells from HPCs after 10 days of co-culture with lot A $(\mathbf{a}, \mathbf{b})$ and lot B (c, d) of BM-MSCs that were exposed to (white bars) or not exposed to (black bars) 0.1 Gy $\gamma$-radiation. The numbers of $\mathrm{CD} 45^{+}$cells, $\mathrm{CD} 34^{+}$cells, $\mathrm{CD} 34^{+} \mathrm{CD} 38^{-}$cells, and $\mathrm{CD} 34^{+} \mathrm{CD} 38^{+}$cells are shown in $(\mathbf{a}, \mathbf{c})$. Data are mean values $\pm \mathrm{SD}$. $n=5$ per group. *, $p<0.05$. Representative dot plots of CD34 versus CD38 expression are shown in (b, d). Numbers in each box indicate the percentage of cells

associated molecules, the mRNA expression levels of angiopoietin-1 (Ang-1), jagged-1 (Jag-1), leukemia inhibitory factor (LIF), and IL-11 did not differ between Ir-MSCs and non-Ir-MSCs (Fig. 9b). In lot B, the mRNA expression levels of IL-6, SCF, and Flt3L in Ir-
MSCs were similar to those in non-Ir-MSCs (Fig. 9c). When the same experiments were performed using the other three lots of BM-MSCs, there was an increase in mRNA expression of IL-6 in combination with a decrease in mRNA expression of SCF and

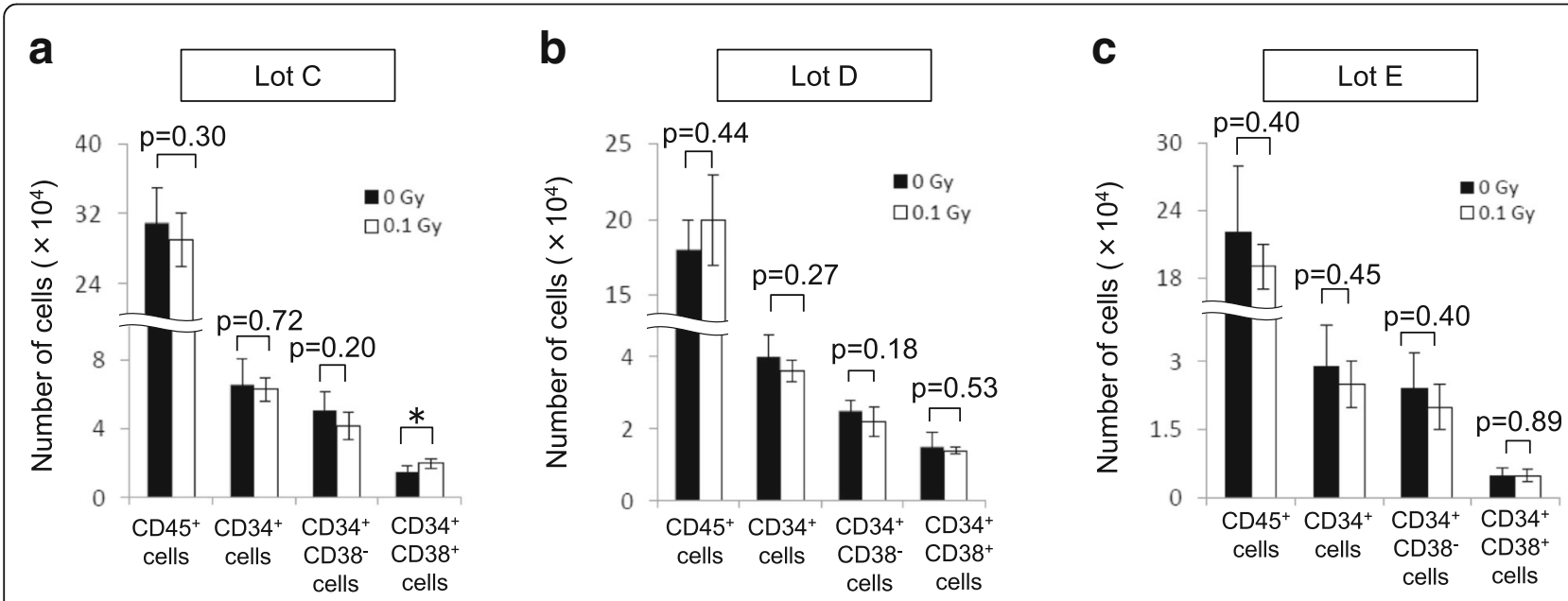

Fig. 8 Generation of hematopoietic cells from HPCs in co-culture with Ir-MSCs. (a-c) The numbers of CD45 ${ }^{+}$cells, CD $34^{+}$cells, CD $34^{+}$CD $38^{-}$cells, and $\mathrm{CD} 34^{+} \mathrm{CD} 38^{+}$cells in co-culture with three different lots of BM-MSCs (lots C, D, and E) that were exposed to (white bars) or not exposed to (black bars) $0.1 \mathrm{~Gy} \gamma$-radiation are shown. Data are mean values \pm SD. $n=5$ per group. ${ }^{*}, p<0.05$ 

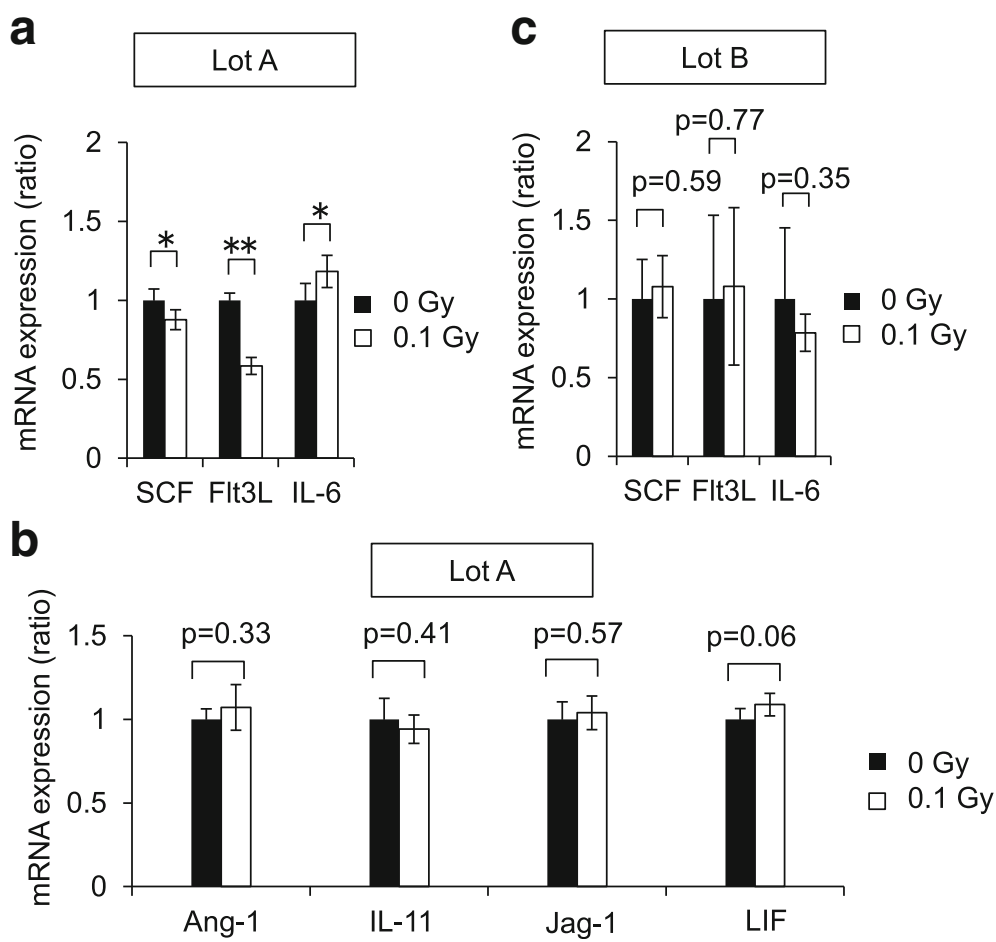

Fig. 9 Expression of hematopoiesis-associated molecules in Ir-MSCs. (a, b) mRNA expression of various hematopoiesis-associated molecules in lot A of BM-MSCs that were exposed to (Ir-MSCS, white bars) or not exposed to (non-Ir-MSCs, black bars) 0.1 Gy -radiation, as assessed by quantitative real-time PCR analysis. Molecules whose expression levels differed between Ir-MSCs and non-Ir-MSCs are shown in (a), whereas those whose expression levels did not differ between Ir-MSCs and non-Ir-MSCs are shown in (b). Expression in Ir-MSCs is shown relative to that in non-Ir-MSCs. Data are mean values \pm SD. $n=5$ per group. ${ }^{*}, p<0.05 ;{ }^{* *}, p<0.01$. (c) mRNA expression of molecules affected in lot A of BM-MSCs was examined in lot B of BMMSCS that were exposed to (Ir-MSCS, white bars) or not exposed to (non-Ir-MSCs, black bars) 0.1 Gy $\gamma$-radiation, as assessed by quantitative real-time $\mathrm{PCR}$ analysis. Data are mean values $\pm \mathrm{SD} . n=5$ per group

Flt3L in lot $\mathrm{C}$ (Table 2). On the other hand, this combined alteration in mRNA expression of IL-6, SCF, and Flt3L was not observed in lots D and $\mathrm{E}$ (Table 2).

\section{Recovery of the altered hematopoiesis-associated characteristics of Ir-MSCs}

Finally, we investigated whether the altered hematopoiesisassociated characteristics of lots A and C of Ir-MSCs recovered. BM-MSCs were cultured for a further 3 weeks after $\gamma$-irradiation (Fig. 5e, late phase). In both lots $\mathrm{A}$ and $\mathrm{C}$, the mRNA expression levels of IL-6, SCF, and Flt3L in Ir-MSCs at the late phase were similar to those in non-Ir-MSCs. In addition, when Ir-MSCs at the late phase were co-cultured with $\mathrm{CD}_{3} 4^{+} \mathrm{HPCs}$, the generation of $\mathrm{CD} 34^{+} \mathrm{CD} 38^{+}$cells was similar to that in co-cultures with non-Ir-MSCs (Table 2).

\section{Discussion}

The stochastic effects of irradiation on the risk of cancers including hematological malignancies are well established [4]. Diagnostic X-rays can increase the risk of cancer [21], and chromosome translocation induced by a single CT scan has been demonstrated at the cellular level [22]. On the other hand, $0.1 \mathrm{~Gy}$ is the threshold of the deterministic effects of irradiation, and low-dose irradiation of equal to or less than $0.1 \mathrm{~Gy}$ is considered

Table 2 Hematopoiesis-associated characteristics of five lots of BM-MSCs that were exposed to 0.1 Gy $\gamma$-radiation.

\begin{tabular}{|c|c|c|c|c|c|c|}
\hline \multirow[b]{2}{*}{ Phase of BM-MSCs after low-dose $\gamma^{- \text {-irradiation }}$} & \multirow[b]{2}{*}{ Characteristics of low-dose $y$-irradiated BM-MSCs } & \multicolumn{5}{|c|}{ Lot of BM-MSCS } \\
\hline & & A & C & B & $\mathrm{D}$ & E \\
\hline \multirow[t]{2}{*}{ Early phase (24 hours) } & Enhanced generation of $\mathrm{CD} 34^{+} \mathrm{CD} 38^{+}$cells from $\mathrm{HPCs}$ & + & + & - & - & - \\
\hline & Increased expression of IL-6/Decreased expression of SCF and Flt3L & + & + & - & - & - \\
\hline \multirow[t]{2}{*}{ Late phase (3 weeks) } & Enhanced generation of $\mathrm{CD}_{3} 4^{+} \mathrm{CD} 38^{+}$cells from HPCs & - & - & n.t. & n.t. & n.t. \\
\hline & Increased expression of IL-6/Decreased expression of SCF and Flt3L & - & - & n.t. & n.t. & n.t. \\
\hline
\end{tabular}




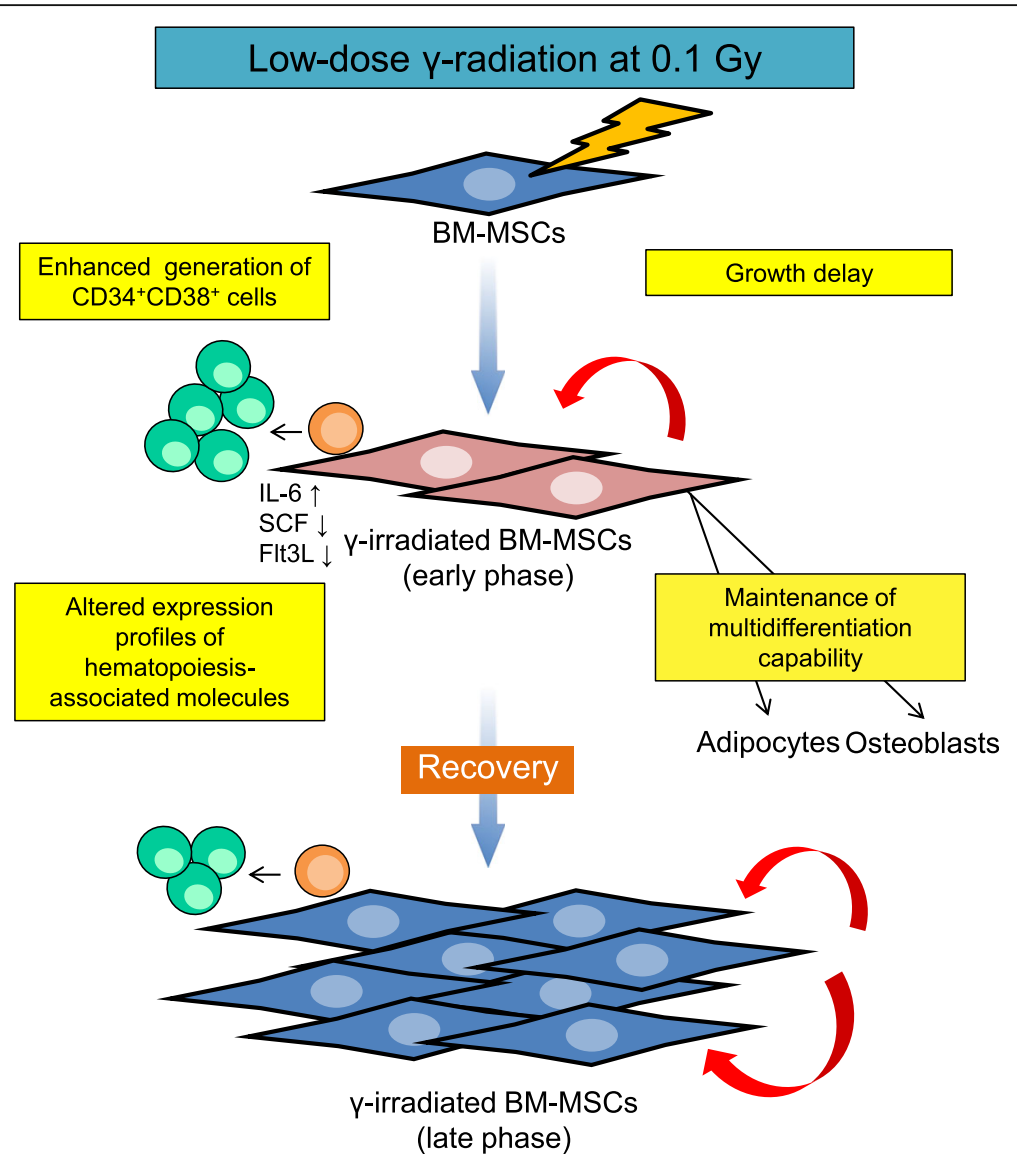

Fig. 10 Graphical summary. Acute exposure to low-dose $y$-radiation ( $0.1 \mathrm{~Gy}$ ) could affect the functional characteristics of human BM-MSCs at the early phase. However, these changes were transient and recovered at the late phase

to have no influence on the risk of diseases apart from malignancies. However, this dose of irradiation can induce somatic mutations or genomic mutations involved in cancer development [23, 24]. Thus, studies to evaluate the effects of low-dose irradiation on tissue or organ functions are required $[25,26]$.

In the microarray analysis presented in this study, cell cycle-associated genes were downregulated in the group of BM-MSCs that showed an expansion delay upon exposure to 0.1 Gy $\gamma$-radiation. Previous studies indicate that low-dose irradiation induces apoptosis and cell cycle arrest in BM-MSCs $[27,28] . \gamma$-radiation at a dose of 0.1 Gy might delay the cell cycle in Ir-MSCs, resulting in the delayed expansion of MSCs. In addition, a gene set consisting of genes that are upregulated in the damaged NCI-60 cell lines after 2 Gy irradiation [20] was highly enriched in the lots of BM-MSCs that showed an expansion delay upon exposure to 0.1 Gy $\gamma$-radiation. BMMSCs could be affected by low-dose $\gamma$-irradiation, even $0.1 \mathrm{~Gy}$, as well as by high-dose $\gamma$-irradiation.

DNA damage occurs upon a single irradiation of 0.1 Gy [27-29]. DNA damage following low-dose Xray exposure was demonstrated in human gingival
MSCs by the formation of phosphorylated histone H2AX and phosphor-S1981 ATM foci [28]. The altered expression of hematopoiesis-associated molecules in Ir-MSCs that was observed in the present study might be affected by DNA damage. However, microarray analysis did not identify enrichment of a gene set related to DNA damage after 0.1 Gy $\gamma$ irradiation. The DNA repair process starts within several minutes after DNA damage and ends after several hours [30]. We speculate that DNA repair was almost complete when total RNA was extracted from Ir-MSCs and non-Ir-MSCs in the present study.

In this study, there were two patterns of the early response to acute exposure to low-dose $\gamma$-irradiation (0.1 Gy) in terms of the hematopoiesis-supportive characteristics of BM-MSCs, namely, BM-MSCs whose supportive capability to generate $\mathrm{CD} 34^{+} \mathrm{CD} 38^{+}$cells from HPCs in co-culture was increased and BM-MSCs whose such characteristics were not affected by lowdose $\gamma$-irradiation. Upregulated IL-6 expression and downregulated SCF and Flt3L expression were observed only in Ir-MSCs whose supportive capability to 
generate $\mathrm{CD} 34^{+} \mathrm{CD} 38^{+}$cells from $\mathrm{HPCs}$ in co-culture was increased. These changes were not observed in IrMSCs whose characteristics were not affected by $\gamma$ irradiation. The difference in the response to $\gamma$ irradiation among multiple lots of BM-MSCs might be related to a difference in sensitivity to $\gamma$-irradiation. This is supported by our findings that multiple differentiation capabilities of Ir-MSCs were not substantially perturbed, regardless of whether their hematopoiesisassociated characteristics were affected. Alternatively, increased expression of IL-6 might reflect cellular senescence due to genotoxic stress in Ir-MSCs [31, 32]. IL-6 contributes to commitment of HPCs toward the myeloid lineage [33]. Therefore, alterations in the expression pattern of these hematopoiesis-associated molecules in Ir-MSCs contributed, at least partially, to the response to $\gamma$-irradiation.

In the present study, the increased supportive capability to generate $\mathrm{CD} 34^{+} \mathrm{CD} 38^{+}$cells from HPCs in co-culture, along with upregulated IL-6 expression and downregulated SCF and Flt3L expression, and the delay in cell expansion were transient in the affected lots of human Ir-MSCs. Transient damage caused by low-dose irradiation has been reported in mouse BMMSCs, in which the expansion speed of mouse BMMSCs was reduced by irradiation at a dose of $0.5 \mathrm{~J} /$ $\mathrm{cm}^{2}$ for 16 and $33 \mathrm{~s}$ and was recovered by $72 \mathrm{~h}$ after irradiation, and nuclear alterations were not detected by 4,6-diamidino-2-phenylindole staining in irradiated mouse BM-MSCs [34]. Further studies are needed to elucidate the exact mechanism that underlies lowdose irradiation-induced functional changes in the characteristics of BM-MSCs.

\section{Conclusions}

We demonstrated that acute exposure to low-dose (0.1 Gy) $\gamma$-radiation could affect the functional characteristics of human BM-MSCs including their hematopoiesis-supportive capability and expansion. These changes were transient, and the characteristics of Ir-MSCs recovered such that they were similar to those of non-Ir-MSCs (Fig. 10). Further research incorporating larger numbers of samples is warranted.

\footnotetext{
Abbreviations

Ang-1: Angiopoietin-1; BM: Bone marrow; cDNA: Complementary DNA; CRNA: Complementary RNA; CT: Computed tomography; FABP4: Fatty acid-binding protein 4; Flt3L: Fms-related tyrosine kinase 3 ligand; GAPDH: Glyceraldehyde-3-phosphate dehydrogenase; GO: Gene Ontology; GSEA: Gene Set Enrichment Analysis; Gy: Gray; H-MSCs: BM-MSCs exposed to 4 Gy Y-radiation; HPCs: Hematopoietic stem/progenitor cells; IL: Interleukin; IrMSCs: BM-MSCs exposed to 0.1 Gy Y-radiation; Jag-1: Jagged-1; LIF: Leukemia inhibitory factor; MNCs: Mononuclear cells; MSCs: Mesenchymal stromal/stem cells; n.s.: Not significant; NCl-60: The 60 cell lines of the National Cancer Institute Anticancer Drug Screen; non-Ir-MSCs: BM-MSCs not exposed to 0.1 Gy Y-radiation; PE: Phycoerythrin; Runx2: Runt-related transcription factor
}

2; SCF: Stem cell factor; SD: Standard deviation; SEA: Single Experiment Analysis; TPO: Thrombopoietin

\section{Acknowledgements}

We thank Ms. Yoko Nakagawa for her excellent technical assistance. The quality checking of total RNA (Agilent 2100 Bioanalyzer), hybridization, scanning (Microarray Scanner G2565CA), and digitization (Agilent Feature Extraction 11.0.1.1) of the microarray and microarray analysis (GeneSpring GX software) were performed at the Medical Research Support Center, Graduate School of Medicine, Kyoto University, which was supported by the Platform for Drug Discovery, Informatics, and Structural Life Science from the Ministry of Education, Culture, Sports, Science and Technology, Japan.

\section{Funding}

This work was supported in part by a Grant-in-Aid from the Ministry of Education, Culture, Sports, Science, and Technology in Japan (\#26293277 and \#15 K09453, Y.M. and T.I.; \#16H00656, N.S.). This work was also supported by the Program of the network-type Joint Usage/Research Center for Radiation Disaster Medical Science of Hiroshima University, Nagasaki University, and Fukushima Medical University. (Y.M., S.F., and T.I.).

\section{Availability of data and materials}

Not applicable.

\section{Authors' contributions}

AF contributed to the conception and design, collection of data, data analysis and interpretation, and manuscript writing. YM contributed to the conception and design, financial support, collection of data, data analysis and interpretation, and manuscript writing. Ml contributed to the conception and design, collection of data, and data analysis and interpretation. SF contributed to the data analysis and interpretation. NS contributed to the data analysis and interpretation. $\mathrm{HH}$ contributed to the conception and design, and data analysis and interpretation. AA contributed to the data analysis and interpretation. TM contributed to the conception and design, financial support, data analysis and interpretation, and manuscript writing. TI contributed to the conception and design, financial support, data analysis and interpretation, and manuscript writing. All authors read and approved the final manuscript.

\section{Ethics approval and consent to participate}

BM samples from healthy adult volunteers were purchased from AllCells (Emeryville, CA). Ethical approval and consent to participate are not applicable.

Consent for publication

Not applicable.

Competing interests

The authors declare no conflicts of interest.

\section{Publisher's Note}

Springer Nature remains neutral with regard to jurisdictional claims in published maps and institutional affiliations.

\footnotetext{
Author details

'Department of Transfusion Medicine and Cell Therapy, Kyoto University Hospital, 54 Kawaharacho, Shogoin, Sakyo-ku, Kyoto 606-8507, Japan. 2Division of Gastroenterology and Hematology, Department of Medicine, Shiga University of Medical Science, Setatsukinowacho, Otsu, Shiga 520-2192, Japan. ${ }^{3}$ Department of Hematology/Oncology, Graduate School for Medicine, Kyoto University, 54 Kawaharacho, Shogoin, Sakyo-ku, Kyoto 606-8507, Japan. ${ }^{4}$ Department of Hematology and Oncology, Research Institute for Radiation Biology and Medicine, Hiroshima University, 1-2-3 Kasumi, Minamiku, Hiroshima 734-8553, Japan.
} 
Received: 7 April 2017 Accepted: 10 July 2017

Published online: 01 September 2017

\section{References}

1. Kitahara CM, Linet MS, Rajaraman P, Ntowe E, Berrington de González A. A new era of low-dose radiation epidemilogy. Curr Environ Health Rep. 2015; 2:236-49.

2. Little MP, Azizova TV, Bazyka D, Bouffler DS, Cardis E, Chekin S, et al. Systematic review and meta-analysis of circulatory disease from exposure to low-level ionizing radiation and estimates of potential population mortality risks. Environ Health Perspect. 2012;120:1503-11.

3. Chodick G, Bekiroglu N, Hauptmann M, Alexander BH, Freedman DM, Doody MM, et al. Risk of cataract after exposure to low doses of ionizing radiation: a 20-year prospective cohort study among US radiologic technologists. Am J Epidemiol. 2008;168:620-31.

4. Leuraud K, Richardson DB, Cardis E, Daniels RD, Gillies M, O'Hagan JA, et al. lonising radiation and risk of death from leukaemia and lymphoma in radiation-monitored workers (INWORKS): an international cohort study. Lancet Haematol. 2015;2:e276-81.

5. Miura Y. Human bone marrow mesenchymal stromal/stem cells: current clinical applications and potential for hematology. Int J Hematol. 2016;103: 122-8.

6. Kato K, Kuwabara M, Kashiwakura I. The influence of gender- and agerelated differences in the radiosensitivity of hematopoietic progenitor cells detected in steady-state human peripheral blood. J Radiat Res. 2011;52: 293-9.

7. Wang C, Oshima M, Sashida G, Tomioka T, Hasegawa N, Mochizuki-Kashio $M$, et al. Non-lethal ionizing radiation promotes aging-like phenotypic changes of human hematopoietic stem and progenitor cells in humanized mice. PLoS ONE. 2015;10:e0132041.

8. Yamaza T, Miura Y, Akiyama K, Bi Y, Sonoyama W, Gronthos S, et al. Mesenchymal stem cell-mediated ectopic hematopoiesis alleviates agingrelated phenotype in immunocompromised mice. Blood. 2009;113: 2595-604.

9. Iwasa M, Miura Y, Fujishiro A, Fujii S, Sugino N, Yoshioka S, et al. Bortezomib interferes with adhesion of B cell precursor acute lymphoblastic leukemia cells through SPARC up-regulation in human bone marrow mesenchymal stromal/stem cells. Int J Hematol. 2017;105:587-97.

10. Dominici M, Le Blanc K, Muller I, Slaper-Cortenbach I, Marini F, Krause D, et al. Minimal criteria for defining multipotent mesenchymal stromal cells. The International Society for Cellular Therapy position statement. Cytotherapy. 2006:8:315-7.

11. Sugino N, Miura Y, Yao H, Iwasa M, Fujishiro A, Fujii S, et al. Early osteoinductive human bone marrow mesenchymal stromal/stem cells support an enhanced hematopoietic cell expansion with altered chemotaxis- and adhesion-related gene expression profiles. BBRC. 2016;469:823-9.

12. Ma Q, Peng Z, Wang L, Li Y, Wang K, Zheng J, et al. miR-19a correlates with poor prognosis of clear cell renal cell carcinoma patients via promoting cell proliferation and suppressing PTEN/SMAD4 expression. Int J Oncol. 2016;49: 2589-99.

13. Albarracin L, Kobayashi $H$, lida $H$, Sato N, Nochi T, Aso H, et al. Transcriptomic analysis of innate antiviral immune response in porcine intestinal epithelial cells: influence of immunobiotic Lactobacilli. Front Immunol. 2017:8:57.

14. Zhao S, Cai J, Li J, Bao G, Li D, Li Y et al. Bioinformatic profiling identifies a glucose-related risk signature for the malignancy of glioma and the survival of patients. Mol Neurobiol. 2016 doi:10.1007/s12035-016-0314-4

15. Iguchi T, Nambara S, Masuda T, Komatsu H, Ueda M, Kidogami S, et al. miR146a polymorphism (rs2910164) predicts colorectal cancer patients' susceptibility to liver metastasis. PLoS ONE. 2016;11:e0165912.

16. Nambara S, Iguchi T, Oki E, Tan P, Maehara Y, Mimori K. Overexpression of CXCR7 is a novel prognostic indicator in gastric cancer. Dig Surg. 2016. doi:10.1159/000452977

17. Wu H, Wu R, Chen M, Li D, Dai J, Zhang Y, et al. Comprehensive analysis of differentially expressed profiles of LncRNAs and construction of miR-133b mediated ceRNA network in colorectal cancer. Oncotarget. 2017;8: 21095-105.

18. Sham A, Moustafa K, Al-Shamisi S, Alyan S, Iratni R, AbuQamar S. Microarray analysis of Arabidopsis WRKY33 mutants in response to the necrotropic fungus Botrytis cinerea. PLoS ONE. 2017;12:e0172343.
19. Yao H, Miura Y, Yoshioka S, Miura M, Hayashi Y, Tamura A, et al. Parathyroid hormone enhances hematopoietic expansion via upregulation of cadherin11 in bone marrow mesenchymal stromal cells. Stem Cells. 2014;32:2245-55.

20. Amundson SA, Do KT, Vinikoor LC, Lee RA, Koch-Paiz CA, Ahn J, et al. Integrating global gene expression and radiation survival parameters across the cell lines of the National Cancer Institute Anticancer Drug Screen. Cancer Res. 2008;68:415-24.

21. Gonzalez AB, Darby S. Risk of cancer from diagnostic X-rays: estimates for the UK and 14 other countries. Lancet. 2004;363:345-51.

22. Abe Y, Miura T, Yoshida MA, Ujiie R, Kurosu Y, Kato N, et al. Analysis of chromosome translocation frequency after a single $C T$ scan in adults. J Radiat Res. 2016;57:220-6.

23. The 2007 Recommendations of the International Commission on Radiological Protection ICRP Publication 103. The International Commission on Radiological Protection 2007.

24. Brenner DJ. We don't know enough about low-dose radiation risk. Nature news (2011). doi:10.1038/news. 2011.206

25. Coleman MA, Sasi SP, Onufrak J, Nataarajan M, Manickam K, Schwab J. Low dose radiation affects cardiac physiology: gene networks and molecular signaling in cardiomyocytes. Am J Physiol Heart Circ Physiol. 2015; 309:1947-63.

26. Nakajima H, Yamaguchi Y, Yoshimura T, Fukumoto M, Todo T. Fukushima simulation experiment: assessing the effects of chronic low-dose-rate internal 137Cs radiation exposure on litter size, sex ratio, and biokinetics in mice. J Radiat Res. 2015;56:129-35.

27. Alessio N, Del Gaudio S, Capasso S, Di Bernardo G, Cappabianca S, Cipollaro $M$, et al. Low dose radiation induced senescence of human mesenchymal stromal cells and impaired the autophagy process. Oncotarget. 2015;6:8155-66

28. Osipov AN, Pustovalova Grekhova A, Eremin P, Vorobyova N, Pulin A, et al Low doses of X-rays induce prolonged and ATM-independent persistence of $\mathrm{YH} 2 \mathrm{AX}$ foci in human gingival mesenchymal stem cells. Oncotarget. 2015;6:27275-87.

29. Laurent A, Blasi F. Differential DNA damage signaling and apoptotic threshold correlate with mouse epiblast-specific hypersensitivity to radiation. Development. 2015;142:3675-85.

30. Vilenchik MM, Knudson AG. Endogenous DNA double-strand breaks: production, fidelity of repair, and induction of cancer. PNAS. 2003;100:12871-6.

31. Coppé JP, Patil CK, Rodier F, Sun Y, Muňoz DP, Goldstein J, et al. Senescence-associated secretory phenotypes reveal cell-nonautonomous function of oncogenic RAS and the p53 tumor suppressor. PLoS Biol. 2008;6: 2853-68.

32. O'Hagan-Wong K, Nadeau S, Carrier-Leclerc A, Aablaza F, Hamdy R, ShumTim D, et al. Increased IL-6 secretion by aged human mesenchymal stromal cells disrupts hematopoietic stem and progenitor cells' homeostasis. Oncotarget. 2016;7:13285-96

33. Ikebuchi K, Wong GG, Clark SC, Ihle JN, Hirai Y, Ogawa M. Interleukin 6 enhancement of interleukin 3-dependent proliferation of multipotential hematopoietic progenitors. Proc Natl Acad Sci U S A. 1987;84:9035-9.

34. Barboza CA, Ginani F, Soares DM, Henriques AC, Freitas RA. Low-level laser radiation induces in vitro proliferation of mesenchymal stem cells. Einstein (Sao Paulo). 2014;12:75-81.

\section{Submit your next manuscript to BioMed Central and we will help you at every step:}

- We accept pre-submission inquiries

- Our selector tool helps you to find the most relevant journal

- We provide round the clock customer support

- Convenient online submission

- Thorough peer review

- Inclusion in PubMed and all major indexing services

- Maximum visibility for your research

Submit your manuscript at www.biomedcentral.com/submit 